\title{
Development Of Sustainable Tourism Industry Along Chaophraya River
}

Supada Sirikudta, Srinakharinwirot University, Thailand

Paiboon Archarungroj, Srinakharinwirot University, Thailand

Sirivan Serirat, Suan Dusit Rajabhat University, Thailand

Nuk Gulid, Srinakharinwirot University, Thailand

\begin{abstract}
The purpose of this research is to present marketing mix strategies plans in the development of sustainable tourism industry along Chaophraya River. The samples are 200 thai tourists and 200 foreign tourists who travel along Chaophraya River in Bangkok, Nonthaburi and Ayutthaya in Thailand. This results reveal that the operators should plan their marketing strategies, focusing on distribution channels, promotion and quality of service, so that the Thai and foreign tourists could perceive more than their expectation which would lead to satisfaction. For Thai tourists to revisit in the future operators must consider perception variable in terms of personnel; and push factors in terms of seeking for escape and relaxation, which together had $13.7 \%$ influence. For foreign tourists, operators must consider perception variable in term of personnel, push factors in terms of seeking for different lifestyle and entertainment and pull factor in term of environment quality, which together had $18.1 \%$ influence. Moreover the operators should increase the sustainable tourism such as preserving and public relation of natural environment and have local tourist guide.
\end{abstract}

Keywords: Development, Sustainable Tourism, Tourism Industry, Expectation and Perception, Pull Motivation, Push Motivation, Satisfaction, Behavior, Behavioral trend, Chaophraya River.

\section{INTRODUCTION}

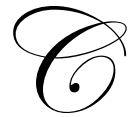

haophraya River is the main river of Thai people and along both sides of the river can be found many attractions including temples, local community lifestyles and agricultural farms. Tourism along the river will help one to see its past and historical changes, as well as the beauty of the art and architecture of each era. The remaining main challenge to the development of the tourism is therefore, how to manage a sustainable industry along the river.

This research paper presents marketing-mix strategies to be employed to the tourism industries along Chaophraya River. The paper studied the motivating factors of both Thai and foreign tourists regarding the influential factors for visiting Chaophraya River and how to gain their satisfactions from 7 marketing-mix strategies, tourism product, price, distributing channel, promotion, personnel development, tourism process improvement and service quality.

\section{OBJECTIVES OF THE RESEARCH}

1. To survey satisfaction, motivation factors (pull factors and push factors), behavior and behavioral trend of tourists toward traveling along Chaophraya River.

2. To identify of sustainable tourism industry along Chaophraya River development guidance. 


\section{LITERATURE REVIEWS}

\section{Tourism Management Concept}

Sustainable tourism development meets the needs of present tourists and host regions while protection and enhancing opportunity for the future. It is envisaged as leading to management of all resources in such a way that economic, social, and aesthetic needs can be fulfilled while maintaining cultural integrity, essential ecological processes, biological diversity, and life support systems" (World Tourism Organization: WTO)

Tourism management of Eber (1992) compose of ten dimensions but only four were used in this research; 1) Using Resource Sustainably, 2) Reducing Over-consumption and waste, 3) Maintain diversity, 4) Supporting Local Economy

The measurements of sustainable tourism include a eleven-items scales. The Cronbach's Alpha in this study is .9076

\section{Expectation and perception toward Service Marketing Mix}

Comparison of expectation and perception for studying satisfaction of tourists by Parasuraman concept (Parasuraman; et. al, $1988: 16$ ) and the study expectation and perception toward service marketing mix by Kotler and Keller concept (2000 : 513) which included tourism products (Boat components and Sightseeing product component), price, place, promotion, people, process and services quality. The measurements consist of the same questions of expectation and perception. The Cronbach's alpha of expectation and perception are .9243 and .9214 consequently. Motivation (Yoon; \& Uysal. 2005) Motivation consist of Push factor and Pull factor. Push factor is the motivation of tourists who want to escape from regular job and searching the experience. However Pull factor is the motivation from traveling place along Chaophraya River by motivating the tourists to travel along Chaophraya River.

The measurements consist 13 push factor and 8 pull factor. The Cronbach's Alpha of push factor and pull factor are .8701 and .8448 consequently. Researcher applied concept of consumer behavior (Schiffman; \& Kanuk. 2007) for behavior and trend of traveling along Chaophraya River. Sustainable tourism concept (Eber. 1992) is sufficient use of resources, decrease consumption and use other resources for culture promotion. The measurements of behavior (Liking Level of Tourism product) include 5 items and trend to revisit along Chaophraya River include 4 items. The Cronbach's alpha of behavior and behavioral trend are .6575 and .8752 consequently.

\section{CONCEPTUAL FRAMEWORK}

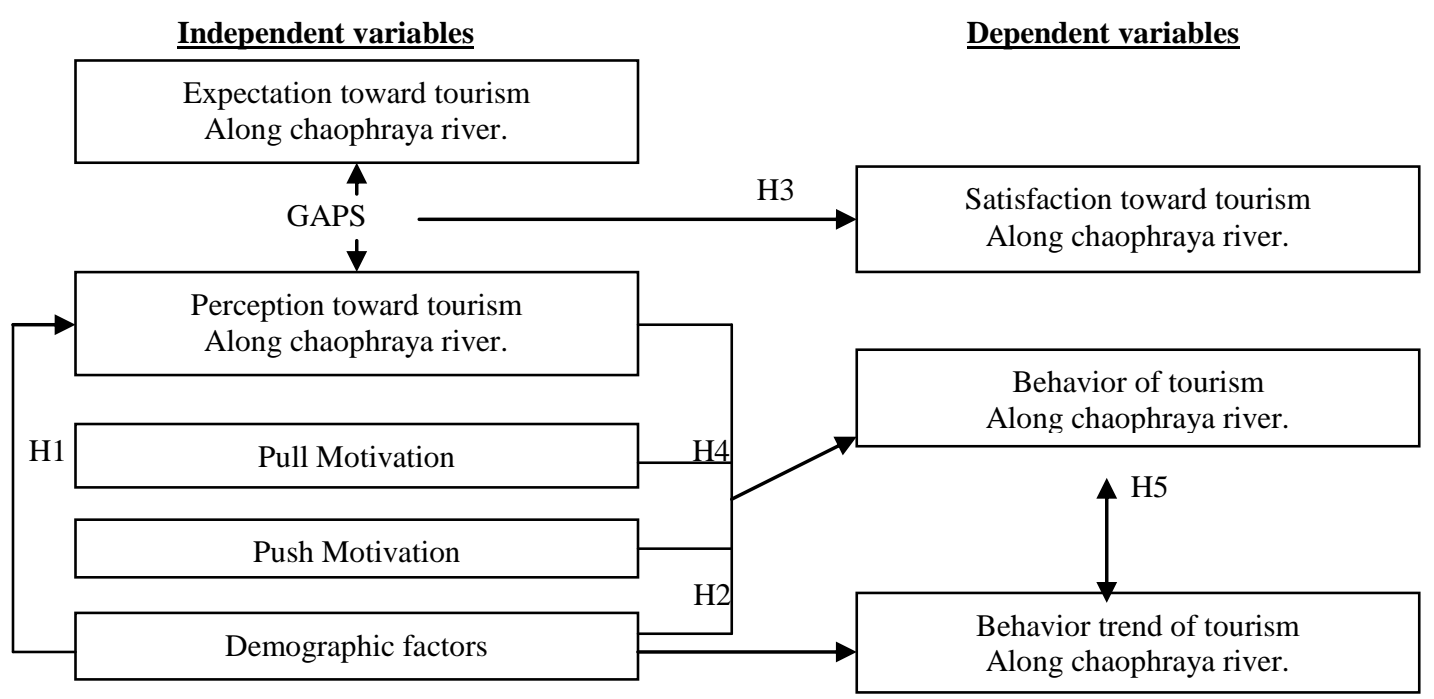




\section{HYPOTHESES}

follows:

Five hypotheses for testing the determinations of tourist satisfaction and trend to revisit in the future as

$\mathbf{H}_{1}$ : $\quad$ There are positive relationships between demographic factors and perception toward tourism along Chaophraya River.

$\mathbf{H}_{2}$ : There are positive relationships between demographic factors and trend to revisit in the future.

$\mathbf{H}_{3}: \quad$ There are comparison expectation and perception toward tourism of Chaophraya River.

$\mathbf{H}_{4}$ : There are positive relationships between perception, pull factor, push factor and demographic factors and trend to revisit in the future.

$\mathbf{H}_{5}$ : There is positive relationship between tourism behavior and trend to revisit in the future.

\section{RESEARCH METHODOLOGY}

\section{Population} Thailand.

Thai and foreign tourists who traveling along Chaophraya River in Bangkok, Nonthaburi and Ayutthaya in

\section{Sample Size}

We can find the sample size of each province by using the formula of unknown population size as follows:

$$
\begin{aligned}
\mathrm{n} & =\frac{Z^{2} \mathrm{Pq}}{e^{2}} \\
& =\frac{1.96)^{2}(0.05)(0.05)}{(.05)^{2}}=385
\end{aligned}
$$

Hence, we increase the amount of sample size of each province to 15 respondents. The total sample size of this study is 400 respondents.

\section{Sampling method methodology}

Three non-probability sampling techniques; Quota Sampling, judgmental sampling and convenience sampling are employed in this study. Researcher employs judgmental sampling to select the locations to recruited tourists, convenience sampling was also employed for distribution a questionnaire to customers.

Statistical analysis includes Descriptive statistics: Mean, Percentage, Standard deviation. Inferential statistics: ttest, One-way ANOVA, Dependent t-test, Pearson Correlation Coefficient and Multiple Regression Analysis.

\section{RESULT}

\section{Respondent profile}

The results of the research were:

1. Majority of Thai tourists who travel along Chaophraya River is female, age between 25-34 years old, single, undergraduate educational level, business employees, has a personal monthly income 10,000-20,000 baht, central resident in Thailand. But majority of foreign tourists are female, age between 25-34 years old, single, undergraduate educational level, is businessman/ entrepreneur, personal monthly income 1,0002,000 us $\$$ and living in Thailand. 
2. Expectation and perception towards tourism along Chaophraya River, push factor, pull factor sustainable tourism, satisfaction in tourism, trend in revisit Chaophraya River are calculated as shown in Table 1 and 2

Table 1

Descriptive Statistics of comparative Expectation and Actual perception towards Service marketing 7 dimension in tourism along Chaophraya river for Thai tourists and foreign tourists

\begin{tabular}{|c|c|c|c|c|c|c|c|c|}
\hline \multirow{2}{*}{$\begin{array}{c}\text { Expectation and Actual } \\
\text { perception towards tourism along } \\
\text { Chaophraya river }\end{array}$} & \multicolumn{4}{|c|}{ Satisfaction for Thai tourists } & \multicolumn{4}{|c|}{ _ Satisfaction for foreign tourists } \\
\hline & $\mathbf{E}$ & $\mathbf{P}$ & $\mathbf{E}>\mathbf{P}$ & Interpretation & $\mathbf{E}$ & $\mathbf{P}$ & $\mathbf{E}>\mathbf{P}$ & Interpretation \\
\hline 1. Tourism Products & 3.83 & 3.57 & 0.26 & Not satisfied & 3.82 & 3.63 & 0.19 & Not satisfied \\
\hline 1.1 Boat components & 3.77 & 3.47 & 0.30 & Not satisfied & 3.78 & 3.57 & 0.21 & Not satisfied \\
\hline $\begin{array}{l}\text { 1.2 Sightseeing product } \\
\text { components }\end{array}$ & 3.92 & 3.72 & 0.20 & Not satisfied & 3.87 & 3.70 & 0.17 & Not satisfied \\
\hline 2. Price & 3.81 & 3.45 & 0.36 & Not satisfied & 3.74 & 3.52 & 0.22 & Not satisfied \\
\hline 3. Place & 3.73 & 3.24 & 0.49 & Not satisfied & 3.74 & 3.52 & 0.22 & Not satisfied \\
\hline 4. Promotion & 3.50 & 3.09 & 0.41 & Not satisfied & 3.64 & 3.40 & 0.24 & Not satisfied \\
\hline 5. People & 4.03 & 3.76 & 0.27 & Not satisfied & 3.86 & 3.67 & 0.19 & Not satisfied \\
\hline 6. Process & 3.92 & 3.51 & 0.41 & Not satisfied & 3.77 & 3.56 & 0.21 & Not satisfied \\
\hline 7. Service quality & 4.06 & 3.87 & 0.19 & Not satisfied & 3.79 & 3.63 & 0.16 & Not satisfied \\
\hline Total & 3.84 & 3.50 & 0.34 & Not satisfied & 3.76 & 3.56 & 0.20 & Not satisfied \\
\hline
\end{tabular}

Table 2

Variables in descriptive statistics are Push factor, Pull factor, Sustainable Tourism Management, Liking Level of Tourism product, Behavior and Trend in tourism along Chaophraya River.

\begin{tabular}{l|cc|cc}
\hline \multicolumn{1}{c|}{ Variable names } & \multicolumn{2}{|c|}{ Thai tourists } & \multicolumn{2}{c}{ Foreign tourists } \\
& Mean & S.D. & Mean & S.D. \\
\hline 1. Push factor & 3.70 & 0.539 & 3.74 & 0.577 \\
2. Pull factor & 3.65 & 0.610 & 3.68 & 0.672 \\
3. Liking Level of Tourism Products along & 3.75 & 0.630 & 3.70 & 0.530 \\
$\quad$ Chaophraya river & 3.29 & 0.760 & 3.35 & 0.720 \\
$\begin{array}{l}\text { 4. Sustainable Tourism Management of } \\
\quad \text { Entrepreneur }\end{array}$ & 4.01 & 0.870 & 3.95 & 0.920 \\
$\begin{array}{l}\text { 5. Behavioral trends in tourism along } \\
\quad \text { Chaophraya Rever }\end{array}$ & & & & \\
\hline
\end{tabular}

In addition, behavior of tourism along Chaophraya River: Thai tourists travel 2 times along Chaophraya River, average time of travel is 4.55 hours, and spend 1,340 baht. However foreign tourists travel 3 times along Choaphraya River, average time of travel is 4.50 hours and spend about 1,662 us\$. Both Thai tourists and foreign tourists prefer to travel during evening/night time, weekend with family. Tourist spot that the tourist must likely to see is temples.

\section{HYPOTHESES TESTING}

The results of hypotheses test are shown as follows:

$\mathbf{H}_{1}$ : Perception toward 7 service marketing mix of foreign tourists has positive relationship with age, educational level, occupation with statistically significant (t-test, One-way ANOVA)

$\mathbf{H}_{2}$ : $\quad$ Trend to revisit along Chaophraya River of foreign tourists has positive relationship with gender with statistically significant (t-test, One-way ANOVA)

$\mathbf{H}_{3}$ : $\quad$ Expectation and perception towards 7 service marketing mix of Thai tourists and foreign tourists have statistically significant. Expectation towards service marketing mix is more than perception. It indicates that both Thai and foreign tourists do not satisfy in all aspects (Paired-t-test) 
$\mathbf{H}_{4}$ : Age of Thai tourists have perception in promotion and they have 1.6\% influence to frequency in travel along Chaophraya River with statistically significant. Thai tourist to revisit in the future must consider perception variable in terms of personnel, and push factors in terms of seeking for escape and relax, which together had $13.7 \%$ influence.

Foreign tourists which have perception to service marketing mix in personnel, push factor (Seeking different lifestyle and entertainment and experience new lifestyle) pull factor (environment quality of Chaophraya River) have influence to frequency in traveling along Chaophraya River which had $17.2 \%$ and foreign tourists, operators must consider perception variable in term of personnel, push factor in term of seeking different lifestyle and entertainment and pull factor in term of environment quality, which had $18.1 \%$ influence with statistically significant as shown in Table 3 (Stepwise Multiple Regression)

Table 3

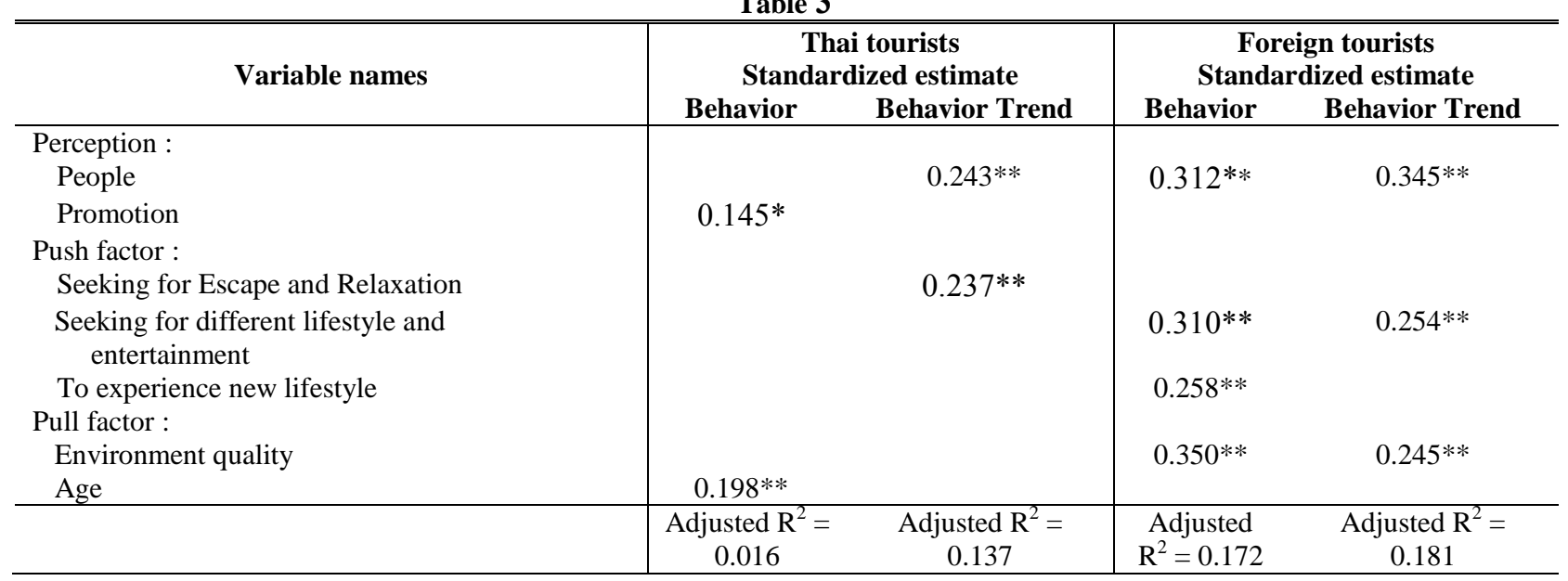

$\mathbf{H}_{5}$ : $\quad$ Behavior (natural, history and culture lover) of Thai and foreign tourists have positive relationship with trend to revisit Chaophraya River with statistically significant (Pearson Correlation)

\section{Recommendations}

The recommendations for developments of Sustainable Tourism are:

1. Operators of sustainable tourism along Chaophraya River should increase satisfaction for tourists by strategic planning in 7 marketing mix as follows:

1.1 Tourism products: For boat components: marketer or operators should increase entertainment onboard boat and allow the tourists to join more activities. They should have variety of foods and drinks provided onboard. Quality of all elements onboard should be checked for safety.

For sightseeing product components: The tourists prefer to see impressive views along Chaophraya River. So operators should get this factor to increase the tourists. In addition we should motivate the employees and tourists in aspect of cleanliness of Chaophraya River by not throwing any garbage to Chaophraya River.

1.2 Price: Variety of prices to choose is pull factor for tourism along Chaophraya River. So, the tour operators should have variety of prices for customers and set the group on Co-op for standard prices.

1.3 Place: Operators should give variety of payment methods, variety of reservation channels such as internet, tour company for convenience in booking or buying and pier at convenient location. 
Operators should provide public relation to tourists

1.4 Promotion: Operators should give information of tourism along Chaophraya River through various medias such as pamphlets, magazines, internet and accessibility of information and recommendation before traveling along Chaophraya River.

1.5 People: Operators should train the employees to get service minds, willingness to provide good service, creating friendly atmosphere and also having language and communication ability.

1.6 Process: Operators should provide convenience in requesting trip changes and alteration, punctuality during the tour process and also prompt service process.

1.7 Service quality: The operators should train all levels of employees to get impressive service quality, honesty and ethics in providing service and increasing confidence in using the service.

2. Influential factors: Government, operators and local community should get sightseeing and impressive tourist spot along Chaophraya River such as natural environment that is uniquely Thai, history, archaeology art and cultures of tourist spots which are pull factor and important push factor are activities with family members.

3. Operators should provide information about impressive service quality, continuing public relation tourism along Chaophraya River. However, government agency and local community should have campaign to preserve environment of Chaophraya River.

4. Tour operators should provide development of sustainable tourism industry by preserve Chaophraya River, natural environment onboard or at tourist spots. They should have separated rubbish bins for different type of rubbish in tourist spots. There is a limit to the number of tourists onboard boat. Information of tourist spot should be provided. Operators have operations that do not have adversely affect environment and society. There is usage of local tourist guide or involvement of local tourist people in tourism activities for increasing revenue to community.

\section{AUTHOR INFORMATION}

Supada Sirkudta, Associate Professor, full-time lecturer in Business Administration Department, Sirnakharinwirot University, she is the Director of MBA program at Srinakharinvirot University since 2006-present. She is an Associate Professor in Accounting Area. She has published about 10 papers in several areas such as management, marketing international business and hospitality and tourism.

Dr. Paiboon Archarungroj, a full-time lecturer in the Business Administration Department, and the deputy director of the of MBA program at Srinakharinwirot University. He received his Ph.D. in Management Sciences from Tsukuba University in Japan. His special areas are on Marketing, Management, Quantitative Analysis, MIS, International Business and Tourism. He has published several papers on International Business and Tourism.

Sirivan Serirat, Associate Professor, full-time lecturer, Graduate school, Suan Dusit Rajabhat University, she was a director of MBA program at Srinakharinwirot University until 2006, her special area is on marketing, international business, Hospitality and tourism. She is a Associate professor in Business Administration Area. She has published about 20 papers in several areas such as management, marketing, international business and hospitality and tourism.

Dr. Nak Gulid, Associate Professor, full-time lecturer in Business Administration Department, Srinakharinwirot University, received two Ph.D., the first doctoral degree is on International trade and finance, University of Missouri-Columbia, U.S.A., the second doctoral degree is on Marketing, Thammasart University, Thailand. His special area is on Marketing, Management, Economics, international business and Hospitality and tourism. He is a deputy director of MBA program at Srinakharinwirot University. He is a Associate Professor in Management Area. He has published about 15 papers in several areas such as management, marketing, international business and hospitality and tourism.

\section{REFERENCES}

1. Assael.H. (1998). Consumer Behavior and Marketing. Action $6^{\text {th }}$ Ed. Cincinnati, Ho: International Thompson Publishing 
2. Eber, S. 1992. Principles for Sustainable Tourism: Beyond the Green Horizon. A Discussion Paper on Principles for Sustainable Tourism. UK. (Unpublished Manuscript)

3. Kotler,Philip and Keller, Kevin Lane.(2009). Marketing Management. $13^{\text {th }}$ ed. New Jersey: Prentice-Hall.

4. $\quad$ Parasuraman, A. ; Zeithaml, V. ; \& Berry, L.(1988). Delivering Quality Service Balancing Customer Perception and Expectation. New York: The Free Press.

5. Philip Kotler. (2000) Marketing Management The Millennium Edition. Prentice Hall International, Inc : Northwestern University

6. Pimonsomphong Chalongsri. 1999. Planning and developing tourism market. Bangkok: Press Kasetsart University.

7. Schiffman, Leon G.and Kanuk, Leslie Lazar.(2000). Consumer Behavior. 7 th ed. New Jersey: PrenticeHall.

$8 . \quad$. (2007). Consumer Behavior. 9 th ed. New Jersey: Prentice-Hall.

9. Serirat Sirivan. (2009) Modern Marketing Management. Bangkok: Taummasarn.

10. Solomon, Michael R. (2002). Consumer Behavior. 5 th ed. New Jersey: Prentice-Hall.

11. Tourism Thailand Organization. 2549. Development of the Bangkok's tourism master plan. Paper 1 (20052009)

12. Yooshik yoon \& Muzaffer Uysal. (2005). An Examination of the Effects of Motivation and Satisfaction on Destination Loyalty: a Structural Model. Tourism Management. Vol.26 (2005). pp. 45-56. 
NOTES 